City University of New York (CUNY)

CUNY Academic Works

Publications and Research

Brooklyn College

2020

\title{
Twelve Dispatches from the Futures of AIDS
}

Alexandra Juhasz

CUNY Brooklyn College

Emily Bass

Pato Hebert

Elton Naswood

Margaret Rhee

See next page for additional authors

\section{How does access to this work benefit you? Let us know!}

More information about this work at: https://academicworks.cuny.edu/bc_pubs/262

Discover additional works at: https://academicworks.cuny.edu

This work is made publicly available by the City University of New York (CUNY).

Contact: AcademicWorks@cuny.edu 


\section{Authors}

Alexandra Juhasz, Emily Bass, Pato Hebert, Elton Naswood, Margaret Rhee, Jessica Whitbread, and Quito Ziegler 


\title{
TWELVE DISPATCHES FROM THE FUTURES OF AIDS
}

\author{
A Dialogue between Emily Bass, Pato Hebert, \\ Elton Naswood, Margaret Rhee, and Jessica Whitbread, \\ with Images by Quito Ziegler and an Introduction by Alexandra Juhasz
}

I am going to switch to the first person here. It's Alex. It's not me smoothed over or mixed in with my coeditors, a gesture and approach that has heretofore signaled our solidarity, compromise, listening, and respect. Those commitments have not left me-not in the least—but I need to write this last introduction from my perspective alone for two reasons. First, I'm not sure how Nishant and Jih-Fei feel about the future right now, as I write this in the summer of 2018, as we wrap up this collection and as the world falls ever more precipitously from beneath our feet, but with every passing day we seem to notice this less-or is it more? - and is that an I or a we? It's hard for me to tell. So, I won't speak of the present for them or on our behalf because the future (of AIDS in and of our world, at least looking out from the besieged and besieging United States in 2018) seems uncertain, yet again, and also violent and desperately sad; and because of this, I can only write about my reading of my colleagues' dispatches about the "Futures of AIDs" with the feeling and honesty that I find, and need, and learn from them, modeled below. Our writers deserve this reciprocity; they gave us their words written in 2017 (and time-stamped, marking these realities of crises) as just this sort of gesture of individual-in-community.

Who are these amazing individuals that you are about to read, how did we find them, and why did they join us? As is true of all the dispatches, and for the collection more generally, to find our contributors, Jih-Fei, Nishant, and I shared and grew our personal connections in the field, keeping our eyes on the significant array of talents, perspectives, locales, and approaches that create and sustain us. 


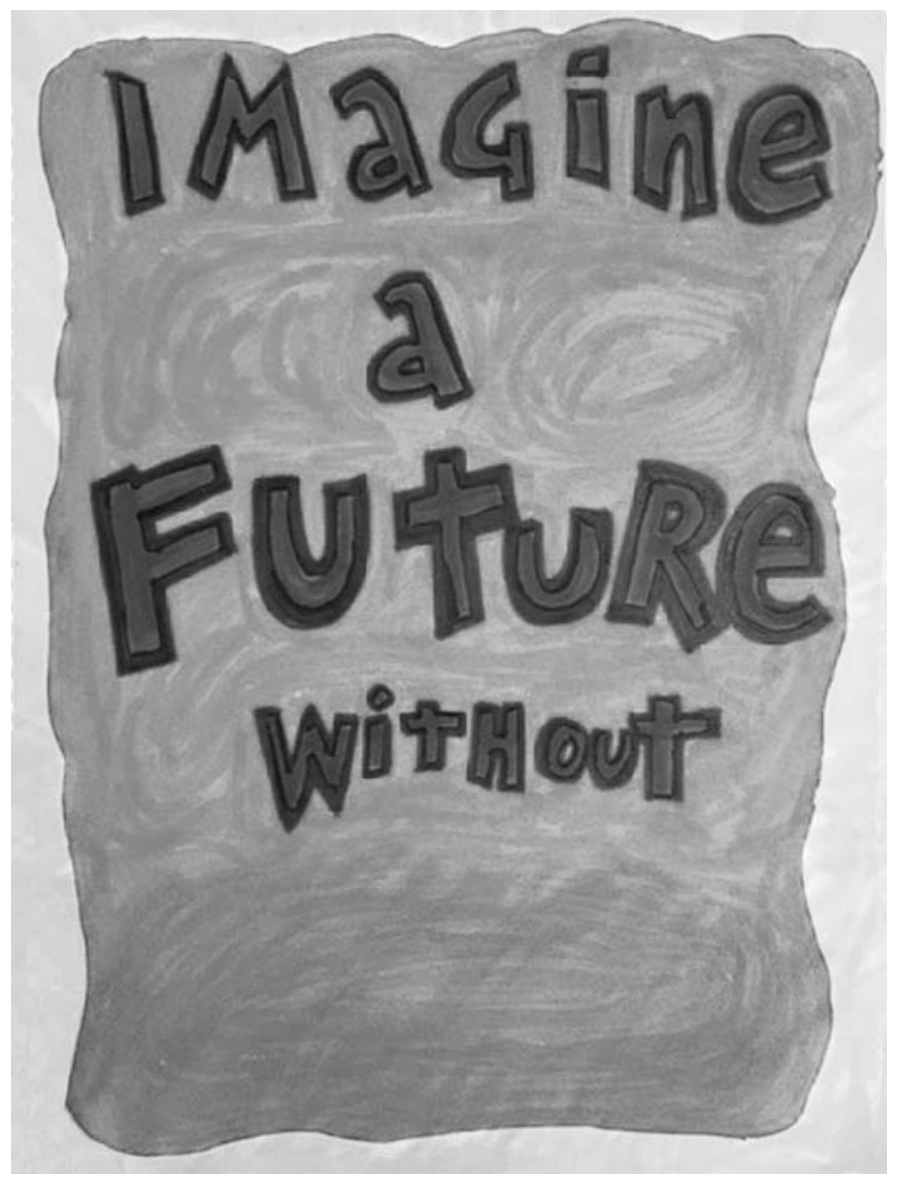

FIGURE 12.1.

Created by

Quito Ziegler.

For this last round of introductions, I would like to take a little time to explain how we came to this particular grouping. My introductions to these contributors follow the circuits by which they came to me (not their order in the text that follows). I know no better way to honor how intellectual, artistic, and activist communities are actually born, shaped, and sustained. Taking time is one way that we claim a hold on our futures. When we find (the time) and work with each other, in any place of crisis, we push against the "dystopian collapse" that Margaret Rhee felt so strongly in 2017. Even if this is only in temporary or rushed engagements - there are so many more places to run, as Emily Bass suggests - or even if we only get to stay still momentarily, rubbing shoulders when we share words on a page. We make space and time for our others. There and then, we remind ourselves that we cohabit our crises, together, for each other. 
Anthologies, asynchronous dispatches, and other places where we fabricate connection evidence our courageous efforts to aspire to and speak together about a difficult present and perhaps a better future, particularly in times and places of fear and despair. I think this defines a good deal of how we have lived through the long and varied lives of HIV/AIDS: our political, communal, and personal responses seem to take all of our effort and mutual commitment in any one moment; and yet, somehow, we find both more time and more of ourselves to give each other later. Critically, these rough but sustaining efforts are often volunteered. This is especially true for the several activists, people with HIV and/or AIDS, and artists in these dispatches for whom writing for us here is not part of any scholarly portfolio. We do this to stay politically alert, to learn from what others have taken the time to learn and make and share, and to invest in the hope "that acts of kindness are stronger than acts of fear and that strong, united hearts can overcome the inequalities of this world," as Jessica Whitbread writes here.

I know Jessica through her contributions to Visual AIDS, an organization with which I, too, often partner, volunteer, and engage. She is also a friend and collaborator of my friend and collaborator Theodore (Ted) Kerr, whom I met when he was working there. Jessica Whitbread often uses her own body and experience as a queer woman living with HIV as the primary site of her work. She puts strong words onto images, like her plastic cross-stitch collaboration with Allyson Mitchell: FUCK POSITIVE wOMEN.

"It is not a silence but a linguistic sliding that is happening," writes Emily Bass about current changes and cuts to international AIDs efforts. Ted also introduced me to Emily. I read her "How to Survive a Footnote: AIDs Activism in the 'After' Years" (Fall 2015) when Ted circulated it for his PDF club, a loose group of readers who came together to read and discuss selected writing about HIV/AIDS. Her health-related journalism circulates widely, and at the same time, she travels in similar social and activist circles to me. Emily is an advocate, communicator, and strategist with twenty years of experience focusing on a rights-based response to HIV prevention and treatment.

"What is powerful is our refusal for unidirectional directions, and our preference for difference and participatory conversation and making," writes Margaret Rhee. I met Margaret when she reached out to me, refusing unidirectionality, because she wanted to engage together around her HIV prison media activist/academic work (her doctoral and activist research and art making), which she connects to the activism and scholarship I conducted during my own doctoral research on AIDs media decades before. A feminist experimental poet, new media artist, and scholar, her research focuses on 
technology and its intersections with feminist, queer, and ethnic studies. I have learned about, and together practiced, such "dynamic ways that grassroots organizing is cultivating a world where AIDs need not overwhelm our very ability to flourish and be free," as Pato Hebert writes here, with many friends and colleagues. Pato and I, too, are longtime collaborators who met first as college teachers but aligned forever through our shared commitments to AIDS activist art making inside and crossing between the academy and AIDS service organizations. He is an artist, educator, and organizer whose work explores the aesthetics, ethics, and poetics of interconnectedness. From this I have benefited, learning from him about the porous boundaries between disenfranchised people, the possibility of their voice in the right circumstances, and our capacities to hear.

Speaking of circumstance needing to be heard, Pato introduced me to his colleague Elton Naswood when they were both at AIDs Project Los Angeles. Jih-Fei also knows Elton through their friend R. Benedito Ferrão. Pato and I had invited Elton to engage with us in a shared art project years ago about activism on the internet. His contributions were steady, eloquent, knowledgeable, and deeply in the space of HIV that is held by Native Americans. According to his bio on the website for the fourteenth Circle of Harmony HIV/AIDs Wellness Conference, he "is of the Near to the Water People Clan, born for the Edge Water People Clan, his maternal grandfather's clan is of the Mexican People, and his paternal grandfather's clan is of the Tangle people, this is how he is Navajo, Dine." I was saddened when he couldn't speak for himself about his view of the future, but I am certain that his silencing will speak some of the volumes we need to and can hear even so: "Repeal of the ACA will lead to AI/ANs having less access to health services, less options for care, worsening health disparities, increased unnecessary suffering, and an increase in preventable deaths."

Expanding possibilities for care in the face of diminished health supports inspires Quito Ziegler to draw their vision of the future in pen and ink: "Imagine a World without Prisons." Imagine no prisons of silence or walls, no prisons of an industrial complex that monetizes suffering and racism expanding and producing the circumstances for the movement and pain of AIDs. I met Quito through their anti-Trump activism and New Yorkbased curatorial projects focusing on gender-nonbinary and trans art and activism with a feminist, antiracist heart. Online, Quito explains many of their interests that brought me to request their artwork for this effort: "They are particularly fond of collective movie-making, organizing an annual intergenerational retreat for queer artists who are surviving or have survived 
transience, and dreaming up the trans-feminist world of the future." ${ }^{2} \mathrm{We}$ see images of their openhanded imagining here. I reached out to them because I had seen these images and thought they might raise all our spirits. I needed that.

Over the two or more years we have been making this book, I have led and read and edited this section many times. I read it again today, in the summer of 2018, right after rereading Cindy Patton's eloquent foreword and our own stately introduction. Writing and reading books, while not crises in the least, are other methods and places for asynchronous, fractured time and place, disruptions of the best kind. Along these lines, the dispatches were written in 2017, my introduction in 2018, and this book will be released in 2020 . The crises we name change. We do not see the world, or our actions in it, as one. Nor are we sages; we can only guess what the future will be. But we are educated, decent people who can learn from history, and each other, about how humans can and do strive to contribute to one of the many futures we might desire. There is always the possibility for hope, or at least action, or words, even as I might feel despair and fear about Trumpism and its powerful steamrollering over what we have already done, and the course of what HIV might be in the future. We are willing to try even so, to imagine, and work, for us I suppose, for nothing more than the reality and hope of us.

All of the many authors of this anthology have done this: worked hard to see and share the violence that has already happened in the past and is being magnified in this present; the fine work that we have done that is being distorted and torn apart; the new work that we will continue to do, even so.

Patton ends her foreword: "Is it happening?" I think it is. All of it: the "capitulation(s)" in "increments and acceptable diction shifts" that Bass saw in 2017 and anticipates more of; the suicides that Whitbread suffers as the brutal AIDs deaths of her day-to-day life; the fact that Naswood cannot speak about and during this administration; the beauty of these efforts, even so. Emily reminds us that "how we speak will pave the road that lies ahead." And Jessica asks, "How can I focus in on you being as open and amazing and wonderful as possible?"

The "shadow gestures" of callous cruelty can be met by our words of overt honesty, intelligence, and self- and communal care. To "Live the Future Now" means to write and read as we want to live, with the furor, fear, pain, and honesty of our time and place, with disruption but without its crisis. 


\section{Prompt 1}

Alexandra Juhasz: The recent election of Donald Trump and his era of Trumpism endangers our future health as humans and as a society. In your first answer, can you reflect upon how current health-related policies and commitments of the current administration affect your/AIDs futures or that of your work/organization (i.e., the repeal of the Affordable Care Act; attacks on reproductive health and Planned Parenthood; the removal of HIV/ AIDs from the White House website; impacts on mental health care, access to substance abuse treatment, and/or disabled populations who rely on Medicaid for independent living, etc.)? What are you doing, what can be done, to insure our ongoing health?

Jessica Whitbread: As a community organizer, artist, activist, academic, and at times a "professional," I am interested in doing work that creates spaces for dialogue about social justice and social change. I do this through public installations, consciousness raising, workshop development and facilitation, engaging in direct action, policy review, research, and any other method that allows a variety of stakeholders to engage in a diversity of ways. I believe that acts of kindness are stronger than acts of fear and that strong, united hearts can overcome the inequalities of this world.

I think that the first thing that needs to be agreed upon is that health is a right and not a privilege. It's been interesting watching the nightmare unfold. My understanding of the impact of the many, many (isn't there some kind of limit to the amount one can have?!) executive orders comes from a global perspective as someone working in sexual and reproductive health and rights in Canada. The impacts of the constant attacks on women, through the global gag order and the proposed defunding of Planned Parenthood, are devastating to any progress made in recent years. Millions of women will lose essential reproductive health services due to these bad policies developed and signed off by rich white men. It's completely gross. This also has a larger impact on women's economic rights that is often underdiscussed. All bodies are under attack under the conservative administration: women's bodies, trans and gender nonconforming bodies, Black and Brown bodies, poor bodies, differently abled bodies, Indigenous bodies, Muslim bodies, HIV positive ... so many bodies. But the good news is these bodies are becoming conscious and uniting to push back against systemic violence. While not always perfect, shifts are being made to work in collaboration to create bridges of understanding about the ways in which we share similar experiences and the ways 


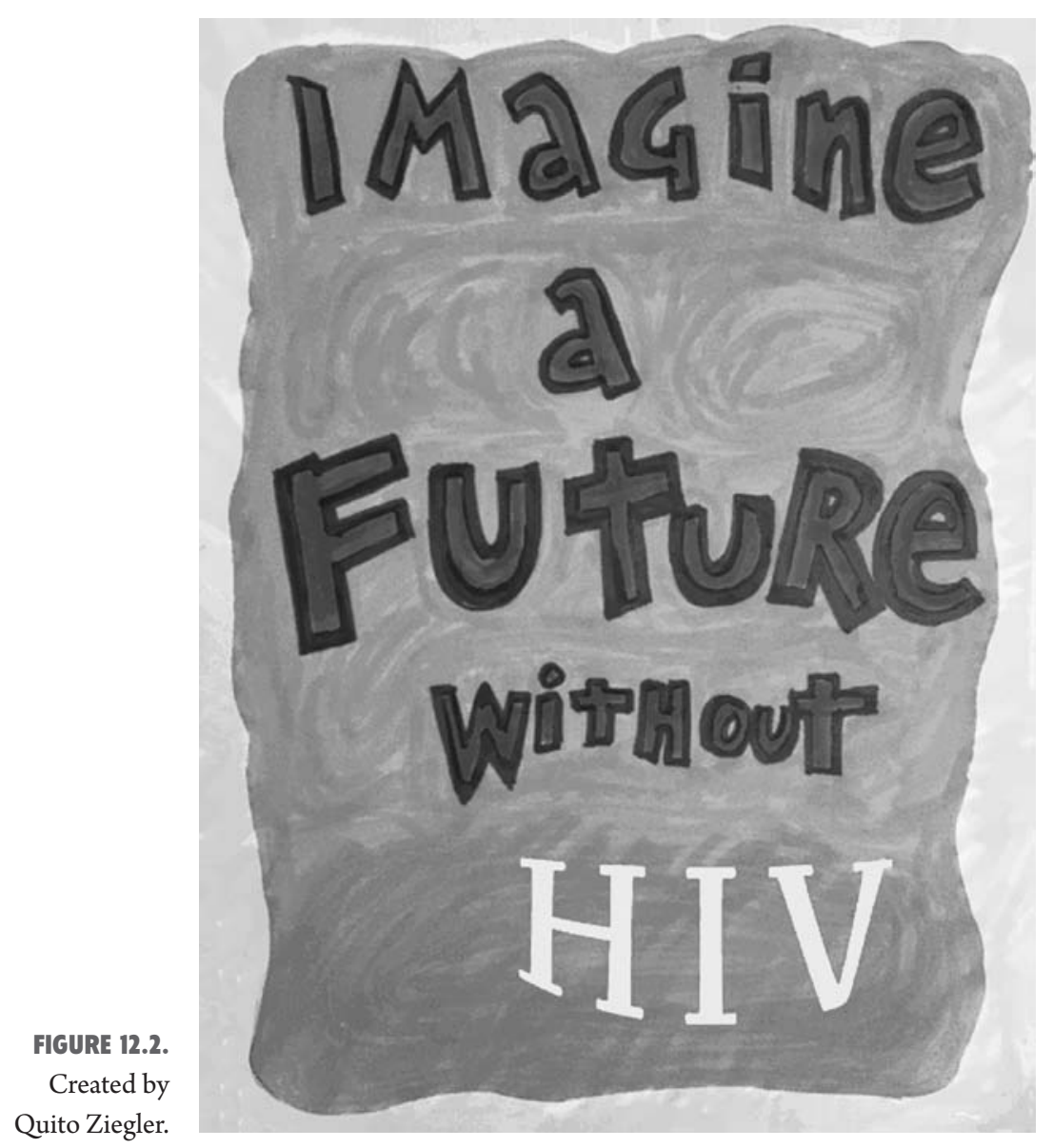

that it has been different. It's been and is going to continue to be tough work but I think that it can be done.

\section{Margaret Rhee}

\section{FROM THE CENTER}

The removal of HIV/AIDS from the White House website is one of many shadow gestures in our postelection times. In the shadows of the Trump administration, these gestures prompt a "whitelash" from larger publics, and a flood of anti-immigrant, anti-health care, anti-Brown, anti-healthy bodies dystopian responses that are antithetical to justice and the work for justice of From the Center (FTC). 
From the Center is a community-based program in partnership with HIV \& Integrated Services (HIVIS, formerly known as Forensic AIDS Project) at the San Francisco Department of Public Health. Established in 1983, HIVIS was the first HIV service provider in a California jail/prison. As part of Jail Health Services, a division of the San Francisco Department of Public Health, HIVIs has successfully implemented HIV prevention and care programs/services in the San Francisco (SF) county jails for over twenty years.

From the Center has a threefold participatory model: pedagogical, technological, and artistic. In our project, incarcerated women utilize low-cost production technologies to create their own short digital stories, involving images and sound, to highlight how their lives are impacted by HIV/AIDS. These stories, in the form of short, narrated moving images or visual collages, serve as powerful educational tools inside and outside the jail setting. The process demonstrates the importance of centering incarcerated women as advocates, researchers, and storytellers of their own lives and communities. From the Center produces today's activist practices-what activist and scholar Alexandra Juhasz outlines in her 1995 book, AIDS TV: Identity, Community, and Alternative Video, as "the alternative AIDs media" and what scholar Priscilla Wald discusses as the stakes of storytelling and HIV/AIDS and inequality. ${ }^{3}$

For example, one of the FTC storytellers created a powerful story titled "Miracle." In her story, Helen Hall insists that the story of Black women and HIV/AIDS is collective: the story of "Ruth," an HIV/AIDS advocate and mother living with HIV/AIDs "is one of them. This is Ruth's story. Which is my story. And your story too."

While we did collaborate with the San Francisco Department of Public Health, our work with FTC can be considered more than "localized." Our collaboration was sporadic and haphazard but also highly organized and powerful: a community of incarcerated, formerly incarcerated women, and academics, or what we prefer to term "inside researchers" and "outside researchers." As a feminist collective, we did not have institutional backing or funding. We found ourselves in allegiance with the parts of institutionsuniversities, research centers, government sectors — that relayed solidarity to our collective feminist vision.

What is powerful is our refusal for unidirectional directions, and our preference for difference and participatory conversation and making. Collaborative was our logics and optics. This comfort in difference and collaboration also shaped our vision for a healthy AIDs future that aimed to protect and centralize women of color. 


\section{HIV/AIDS UNDER OBAMA}

Although From the Center was primarily local, gestures from the national administration under Obama had helped solidify our focus on new media technologies. In the summer of 2010, my collaborator Isela Ford (formerly González) and I were working hard to implement the first workshops in the jail setting. One summer day, we paused from our weekly meeting at the Forensic AIDs Project offices to watch the Obama administration's announcement of the first national comprehensive HIV/AIDs campaign. The formal announcement was livestreamed online.

The formal announcement was a gesture.

The gesture symbolically pushed our own work forward.

The national HIV/AIDS campaign included testimony by then secretary Kathleen Sebelius that pointed to racial and gender inequalities of HIV/ AIDS statistics, particularly for women of color: "We've been very successful at keeping HIV/AIDS incidence low for some populations. If you are a white heterosexual woman, like me, your chances of being infected by HIV and AIDS are very low, 1 in 50,000. But if you're a black female, who is also an injection drug user, your chances of being infected are more than a thousand time higher than mine, 1 in $35 . " 5$

Under the Obama administration, Sebelius offered a particular national story. She pointed out her own raced and gendered body as privileged. The inclusion of race and gender within Obama's national campaign was a gesture that unfolded online, and that seemed to imbue within it our visions of FTC. Obama's campaign and our own inspired from it reside in stark contrast to the current administration's removal of HIV/AIDs from the White House website.

\section{HIV/AIDS UNDER TRUMIP}

Our work-utilizing new media technologies to advocate and express feminist HIV/AIDS futures - is affected by Trump's regime in a variety of ways.

The removal of HIV/AIDS from the national website is a gesture of a dystopian collapse.

If dystopia is a story of a hopeless future, the present may be a collapse of the future into the past.

Yet I am reminded of Helen Hall's artist statement for "Miracle": "Because I want to help women know that it is okay to go through things like that, this life."

The removal of HIV/AIDs from the White House website shows us the stark reality of bodies and their images who are deemed not valuable to the current regime's optics. 


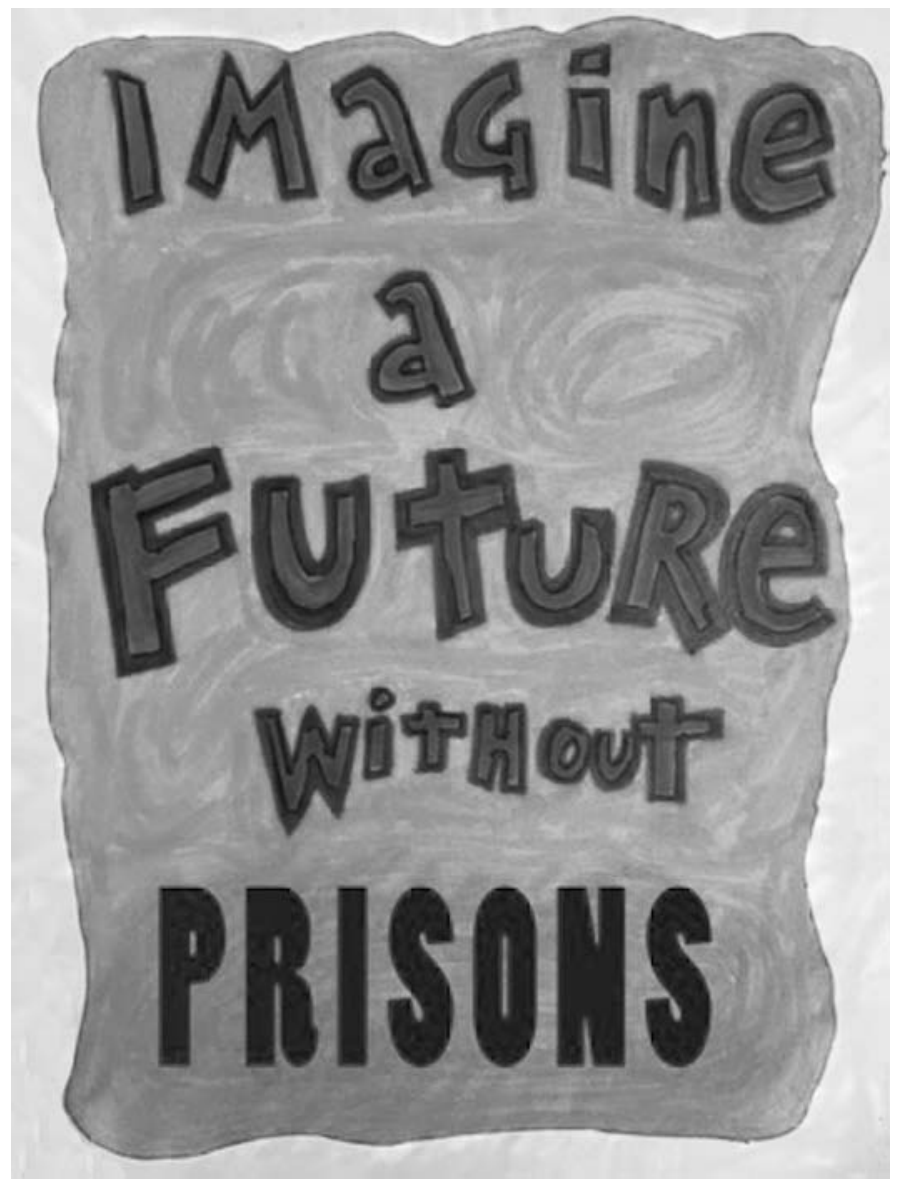

FIGURE 12.3.

Created by

Quito Ziegler.

At the same time, removals reveal the edges of resistance, story, and life to be continually forged.

With darkness comes moonlight

flickering digital screens, this life.

Pato Hebert: I started working in HIV in 1994, and spent some fifteen years engaged in local and national HIV work with queer communities of color in San Francisco, Los Angeles, and New York. But my more recent efforts have been primarily transnational, and it is through this prism that I want to consider our AIDs futures, both the threats afoot as well as the dynamic ways that grassroots organizing is cultivating a world where AIDS need not overwhelm our very ability to flourish and be free. 
My thinking is profoundly indebted to my colleagues at the Global Forum on MSM \& HIV (MSMGF) and our hundreds of partners at local, country, regional, and transnational levels who are working together to deepen a global movement for the health and human rights of queer men, transgender people, sex workers, people who use drugs, and the other communities who are most impacted by HIV/AIDS. Vibrant and evolving, these global networks and their regional and local members are changing HIV responses all over the world. Often known as "key populations" in international HIV advocacy efforts, these communities are more organized and coordinated than ever before. This is exciting, and increasingly crucial.

In late February 2017, US president Donald Trump put forward a preliminary budget plan that would drastically cut funding for USAID and the State Department. These entities oversee the most important US resources for international HIV/AIDS initiatives, including funding for the United States President's Emergency Plan for AIDs Relief (PePfar) and the Global Fund to Fight AIDs, Tuberculosis and Malaria. Community activists and networks around the world have long lobbied for governments, including that of the United States, to contribute their fair share to the international HIV response and work with local movements to uphold normative guidance grounded in evidence-based, rights-affirming harm reduction, and community-led action. Local movements, in turn, leverage these resources to hold their national governments accountable and strive to ensure that HIV responses are targeted to and shaped by the communities who are disproportionately impacted by HIV.

If Trump and his team succeed in cutting the budget as proposed, tens of thousands of people living with HIV will struggle to access the life-saving treatment they deserve, and prevention initiatives will atrophy, thus causing infection rates to once again accelerate. Trump could dangerously set back our achievements at exactly the moment when we should be strengthening and expanding our response to ensure long lives, lower costs, and greater effectiveness worldwide. Statist solutions will never be enough to ensure our wellbeing and pleasure. But the scale of HIv-related challenges cannot adequately be addressed without governments playing their part to ensure nondiscriminatory legal frameworks, build accessible and effective health systems, and honor the invaluable role of community guidance and leadership.

It is refreshing, inspiring, and challenging to work alongside activists from around the world whose urgencies are not primarily determined by US politics. Although many of the structural impediments are shared across contexts, it is worth remembering that locally defined priorities, tactics, 
strategies, and implementation must always take precedence over either topdown or one-size-fits-all approaches. Trump's turbulence may exert great pull, but we cannot be distracted or deterred from the kinds of models being developed in unison at the grassroots global level.

In July 2016, at the International AIDS Conference in Durban, South Africa, the IRGT: A Global Network of Trans Women and HIV worked in partnership with other transgender regional organizations and networks to organize the first ever pre-conference on HIV and transgender people. Titled "No More Lip Service, Trans Access, Equity and Rights, Now!” the historic gathering was so popular that it maxed out its attendance capacity during registration. Now the IRGT is mobilizing trans-identified people to serve as technical advisors in support of trans-led organizing efforts happening regionally in Asia and the Pacific, Sub-Saharan Africa, and Latin America and the Caribbean.

The Global Network of Sex Work Projects (NSWP) has been supporting grassroots peer education efforts between sex workers from across the Global South. Sex workers run their own week-long academy, which offers peer-led workshops, site visits to community-led interventions, and art advocacy sessions. The academy is based in Kenya and convenes teams of sex workers from across Africa and increasingly from other contexts in the Global South, whereby local movements nominate peers for attendance and participation. This is an exemplary popular education model that is shaping the way sex worker movements strengthen and grow across the world. These initiatives include peer paralegal services for sex workers lobbying for their rights in India, and the engagement of sex workers-led organizations in Global Fund processes in Central Asia and Eastern Europe.

The International Network of People who Use Drugs (INPUD) has recently energized its leadership and deepened its work with members to better fight repressive drug policies. It is doing so through improved coordination of the voices and experiences of people who use drugs from around the word. As part of this process, INPUD has developed and launched the Drug User Peace Initiative (DUPI), a series of guiding documents that challenge harmful dogmas related to human rights, the stigmatization of people who use drugs, and the war on the health of such communities. The DUPI instead foregrounds clear and compelling harm-reduction strategies that counter criminalization and social control with progressive approaches to equity and empowerment.

At the Global Forum on MSM \& HIV (MSMGF), we are working with colleagues to challenge the slide toward calcification that can so often occur as social movements congeal into organizations and then institutions. This is 
one of the great ironies and challenges of organizing - that we not simply succumb to shoring up the survival of NG Os or long-standing figureheads and gatekeepers but instead engage and follow the vision of new waves of leadership by transgender people and gay and bisexual men who are coordinating across the Global South in their response to HIV. We helped convene dozens of community leaders and stakeholders to develop the MSMIT (men who have sex with men toolkit), a practical guidance for collaborative interventions that can implement comprehensive HIV and sexually transmitted infection (STI) programs for gay men and other men who have sex with men (MSM).

What works well in one context or movement may not work elsewhere, but we can continue to learn from one another's efforts, tactics, struggles, strategies, and breakthroughs. All around the world, community members have been pushing for a greater role in determining the direction of their countries' responses to HIV/AIDS. A jointly vibrant and equitably distributed future is not guaranteed. We have much work to do, around scaling up testing and treatment initiatives led by communities, debating, prioritizing and resourcing our approaches to prevention, countering stigma and discrimination, and coordinating our responses to co-infections with tuberculosis and especially hepatitis.

As repression rises and resources shrink, there is pressure to take an overly narrow and conventional public health approach. Yet we would be wise to remember the sociocultural dimensions of our work, the structural inequities that challenge it, the criminalization of our lives, the liberation and effectiveness of harm-reduction and sex-positive approaches, and the crucial role that community must continue to play. Trump and his aftershocks will be with us for longer than we care to imagine. But together we must conjure other futures full of possibilities and wellness.

Emily Bass: Since the election, I have been thinking nearly every day about a problem that Madeline Levine, the English translator of Miron Białoszewski's A Memoir of the Warsaw Uprising, describes in her introduction. The book is Białoszewski's account of a sixty-three-day revolt against Nazi occupation in 1944. It is relentlessly plain spoken: "I went here, I went there." Levine's problem is that there are so many ways that Białoszewski used variations on the verb "to run." She writes that she strained to capture the nuances of the words he used to describe the movement of panicked rebels under assault and in flight.

In 2017, how many ways are there to run? Several days a week I go to stand down in Lower Manhattan-hurry to this corner or that one. I get to the 


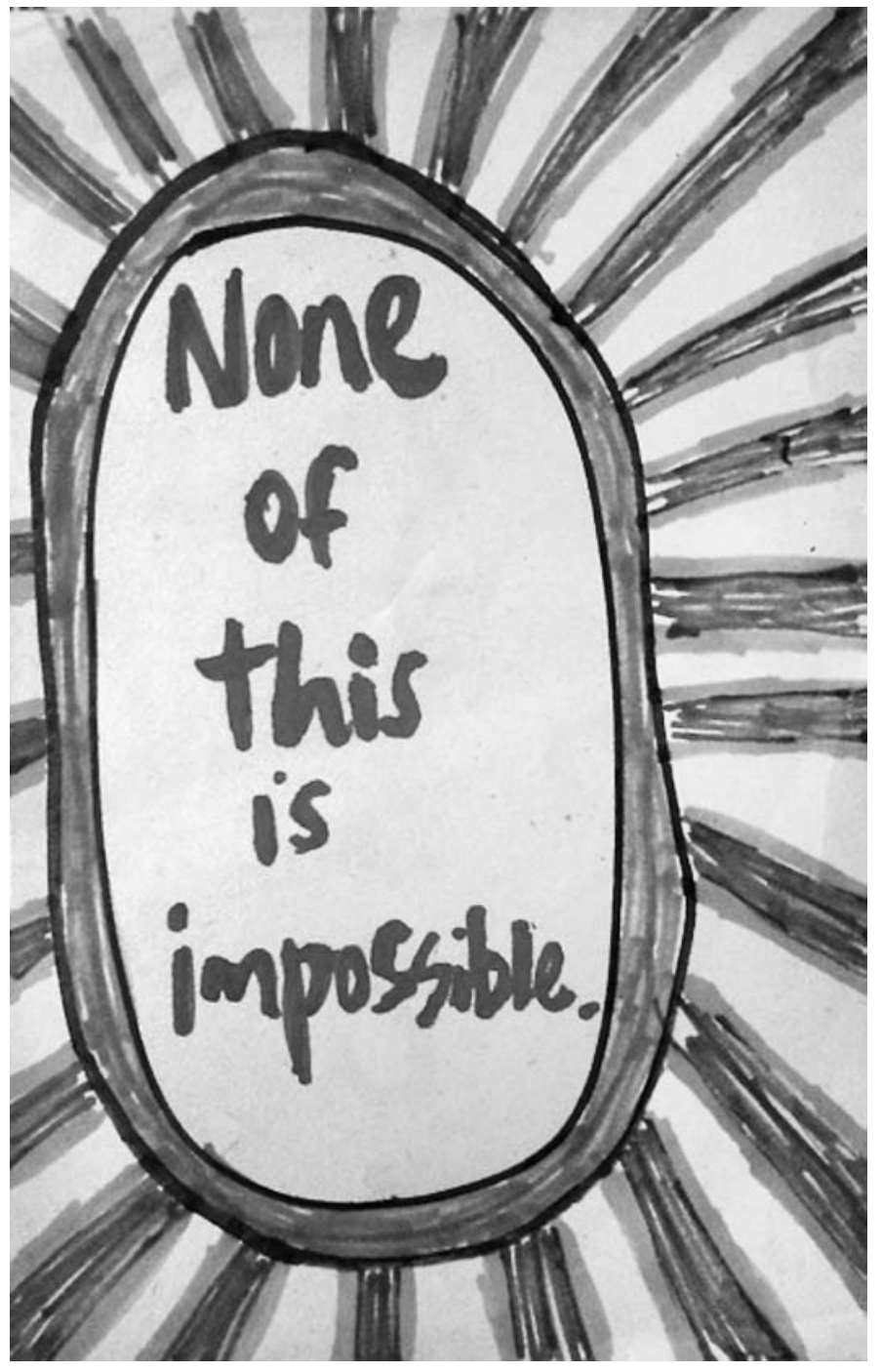

FIGURE 12.4 .

Created by

Quito Ziegler.

corner. Sometimes there's just a few people; sometimes there's a crowd. A few weeks ago, a friend got so tired of carrying signs that she went to a protest with a piece of hot pink duct tape over her mouth. On Tuesdays, I grab food and run down to the ACT UP-infused and -informed Rise and Resist meeting - a new direct action group that was meeting in the old LGBT center until we outgrew its space and moved to the church across the street.

Speaking of that duct tape, my friend wore it on International Women's Day to protest the Global Gag Rule, a bipartisan binary piece of policy: an 
on-off switch that Dems and Republicans toggle on their first or second day in office. Up until now, it has prohibited foreign NGos receiving US foreign assistance dollars from talking about, providing, referring, for or advocating for the legalization of abortion. You can't do these things even if you're doing them with other funds. Prior to 2016, the gag rule was last turned on under President George W. Bush. Then, groups that provide trusted, high-quality health care to women lost their funding; they had to close their doors. Women had to go find contraception elsewhere-or go without. Unplanned pregnancies went up; so, too, did unsafe abortions.

The Global Gag Rule has always been a nasty, hypocritical bit of policy. I expected Trump to reinstate it. But I hadn't expected that he would direct the State Department to apply it to all global health spending - including the $\$ 4$ billion and change that we spend every year on global AIDs.

How many ways are there to run?

Old ACT UP dies hard-and long may it run. But in the health-care breakout group for Rise and Resist, where folks I've known for years and people I've never met sit in circles and try to find a common language across the generational divides of divergent histories and new technologies - "When we did the Wall Street action ..." and "Wait, what's a Slack?"-I'm struck by the struggle to get women's sexual and reproductive health to matter. We do an action about TrumpCare and the phrase family planning gets plopped into the media brief. "Nope," I say, "that's not enough." A revision happens. The next action is on Medicaid Block Grants - it's a gas. Trump's ACA legislation dies and we feel great. But I keep waiting for the moment when the Global Gag Rule-I give an update about it at the Rise and Resist meeting every time I'm there-will become the next fight.

Is the Global Gag Rule narrow and femme-oriented? Is birth control too unqueer? Or is it because the Global Gag Rule always happens when Republicans are in power-people have said this to me-so it feels impossible to change?

I caucus with my duct-tape-wearing friend and other women and we decide not to form a women's health caucus for now. Meanwhile, in my day job directing strategy for an advocacy group focused on HIV prevention and dedicated to working in solidarity with women in East and Southern Africa whose bodies and families are daily impacted by the gag rule, we debate what to do about the portion of our own funding that comes from the US government. To accept the money is to accept the policy; to refuse it is to lose resources for the women who are our allies. We don't directly work on abortion anyway, so our actual work wouldn't be affected, we reason. It's better 


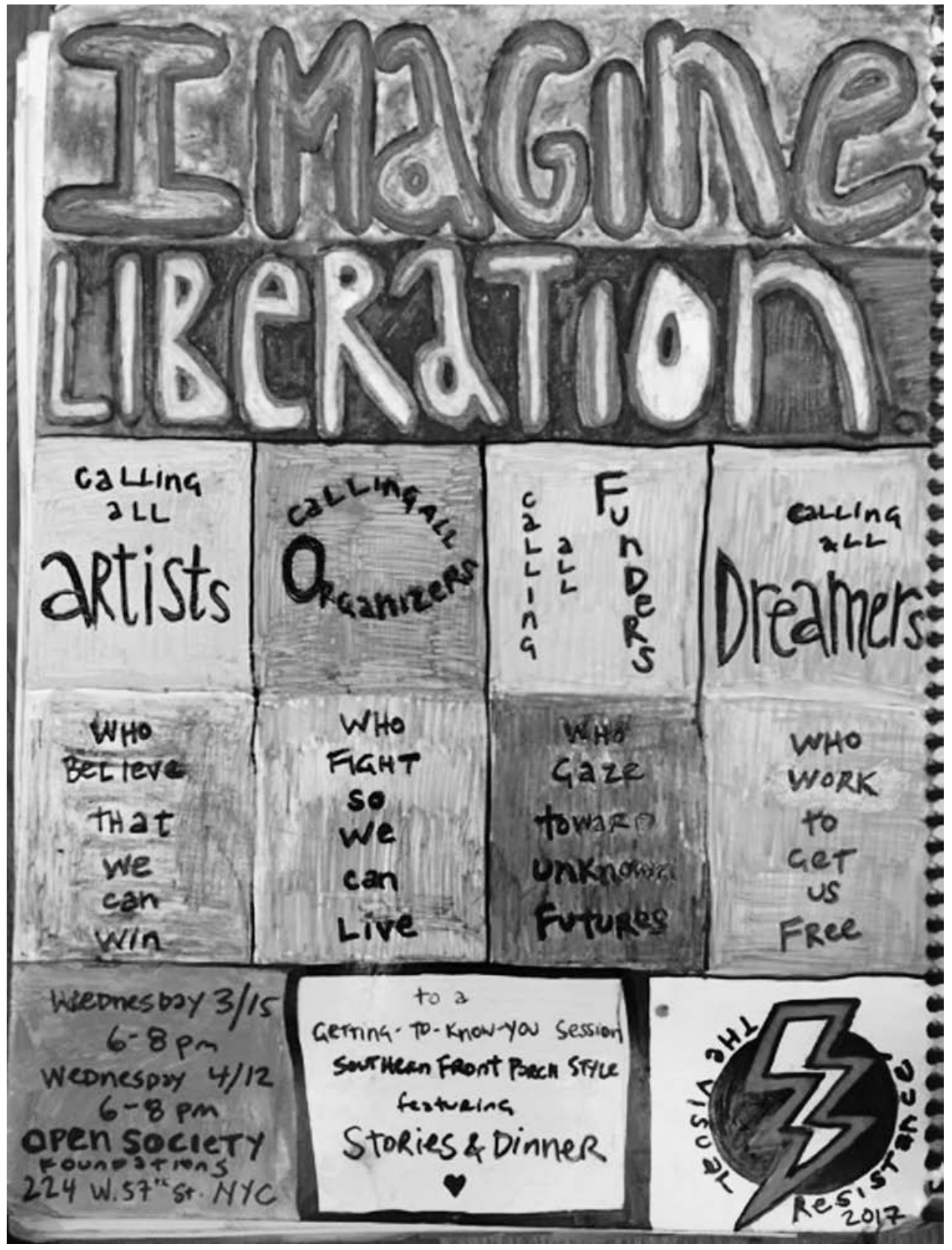

FIGURE 12.5. Created by Quito Ziegler. 
to have the resources and use them well than to take a stand and lose them. But when do we make the first decision that is capitulation, collaboration? Do you know it at the time? I'm scattered here-and that's the point. It's an uprising under assault. Everybody run. We're doing what we rememberACT UP rules of order apply at Rise and Resist-and we're trying to figure out when to split off into smaller groups, and when to hide. I don't have the answers yet about what health looks like now in 2017 and under Trump. My duct-tape friend just started an affinity group of Rise and Resist women to work on the global gag. I've skipped the last few weeks. I'm tired. As for health? Well, PEPFAR's been maligned for its faith-based initiatives and it's a sick patriarchal biblical reading that's driving Vice President Mike Pence, who's undoubtedly behind the gag rule expansion. And I have begun balancing my AIDS work with local work on immigrant justice. I have been running toward meetings in churches by people who are literally running for their lives. I find myself walking into these basements hoping someone might show me how to pray.

Elton Naswood: Unfortunately, I'm not able to respond to the prompt as it is a political question and in my current position as a federal government contractor, I'm not able to give a response. However, below is the summary of the ACA repeal response from the National Indian Health Board and a link to the entire report.

\section{"IMPACT OF ACA REPEAL ON AMERICAN INDIANS AND ALASKA NATIVES," HTTPS:// WWW.COMMONWEALTHFUND.ORG/PUBLICATIONS/ISSUE-BRIEFS/2017/JAN/ REPEALING-FEDERAL-HEALTH-REFORM-ECONOMIC-AND-EMPLOYMENT}

\section{SUMMARY}

Repealing the ACA presents risks beyond access to health services. Analysis recently released by the Commonwealth Fund shows that dire impacts to states will result from repeal, including losses in 2019 of $\$ 140$ billion in federal funding to state budgets, a loss of 2.6 million jobs across all states, with only a third of those jobs being in health care and the rest in other industries as ripple effects. ${ }^{6}$

In Indian Country, it is common that federal programs providing federal services to AI/ANs [American Indians and Alaska Natives], of which health care is a major component, are one of the primary sources of employment for Tribal people. Federal jobs, in many cases, stimulate and grow the local 


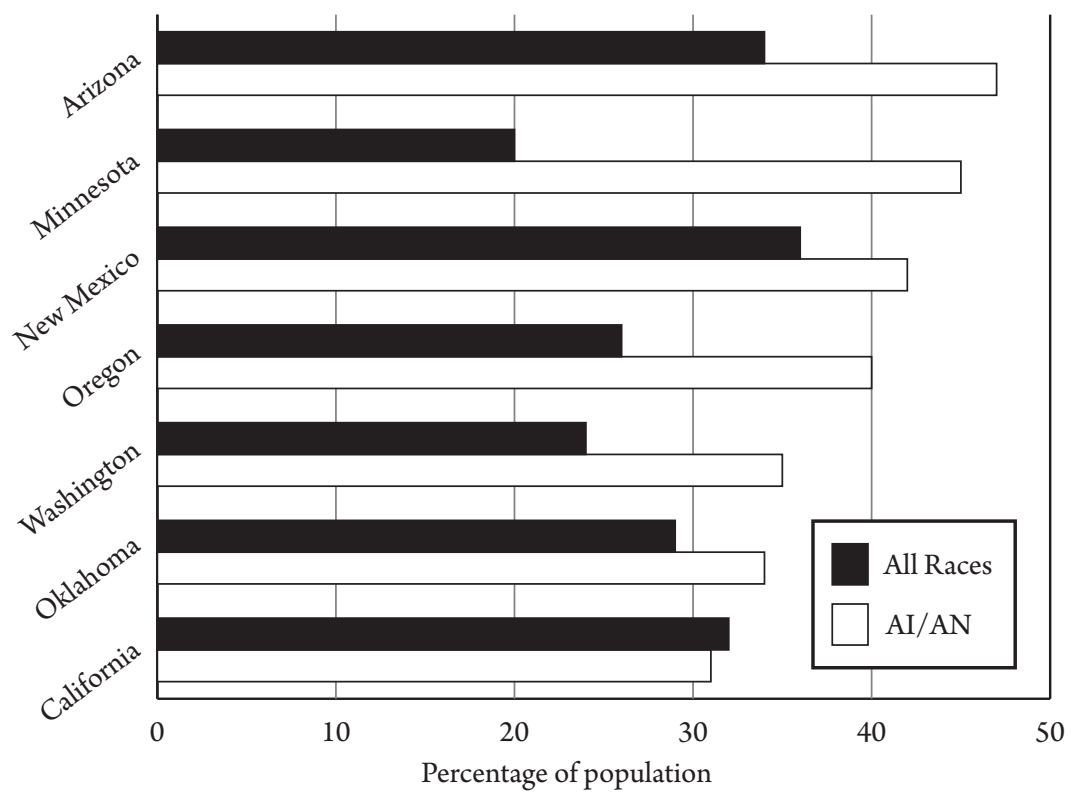

FIGURE 12.6. Percentage of population under 138 percent of the federal poverty level, by state.

economy by providing a rare source of income from the outside. As a result, the impacts on local Tribal economies would likely be even more severeand come at a time when recent improvements from health care reform were starting to take root. Repeal of the ACA will lead to AI/ANs having less access to health services, less options for care, worsening health disparities, increased unnecessary suffering, and an increase in preventable deaths. The issue of repealing the ACA, therefore, should be examined through the lens of treaty responsibilities, social justice, and civil rights. Any attempt to repeal and replace the ACA should leave in its place programs and options that will increase access to direly needed health services, not further limit care for Indigenous Americans.

\section{Prompt 2}

Juhasz: I'd like you to speak to any or many of these following interventions from your colleagues, in a second, brief vision statement about AIDs futures. 


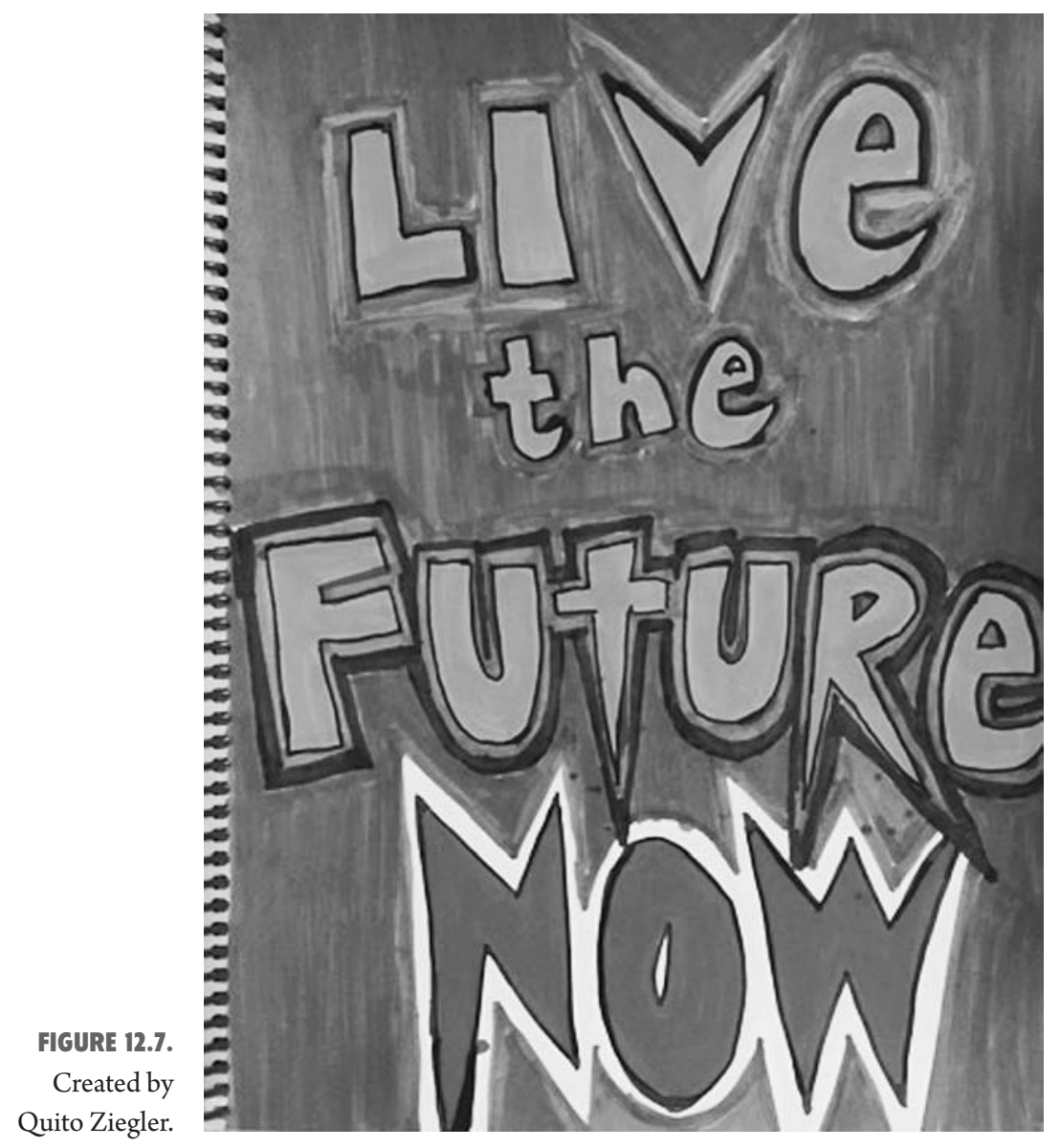

- Removals reveal the edges of resistance, story, and life to be continually forged. (Margaret Rhee)

- We would be wise to remember the sociocultural dimensions of our work, the structural inequities that challenge it, the criminalization of our lives, the liberation and effectiveness of harm-reduction and sex-positive approaches, and the crucial role that community must continue to play. Trump and his aftershocks will be with us for longer than we care to imagine. But together we must conjure other futures full of possibilities and wellness. (Pato Hebert)

- I find myself walking into these basements hoping someone might show me how to pray. (Emily Bass)

- Repeal of the ACA will lead to AI/ANs having less access to health services, less options for care, worsening health disparities, increased 
unnecessary suffering, and an increase in preventable deaths. The issue of repealing the ACA, therefore, should be examined through the lens of treaty responsibilities, social justice, and civil rights. Any attempt to repeal and replace the ACA should leave in its place programs and options that will increase access to direly needed health services, not further limit care for Indigenous Americans. (Elton Naswood)

- But the good news is these bodies are becoming conscious and uniting to push back against systemic violence. While not always perfect, shifts are being made to work in collaboration to create bridges of understanding about the ways in which we share similar experiences and the ways that it has been different. (Jessica Whitbread)

- Any of Quito's images.

Bass: Hello from South Africa, and the far side of a week spent within the US government PEPFAR program. It's an annual gathering to review the plans that each country makes for its coming year. These are called Country Operational Plans or, nearly universally, Cops, so that when you say where you are goingas you head toward the Rosebank Hyatt in Johannesburg, with its pinky-purple art photos of townships-you say you are going to the COP review. This is how America's global AIDs program works: there is an annual gathering to make decisions about how to spend US money_-which accounts for a full two-thirds of the investment in "global" AIDS, a phrase that here means AIDS in Black and Brown bodies living with and at risk of HIv beyond our borders. Perhaps because it is beyond our borders, there is no irony and no wincing that we call this caucus on how to keep Black people healthy the cop review.

Let's look at those cops/cops. Or no, let's not, because the fact that we use this language without wincing or even noticing means that we are doing what America does so well so often: let's look away.

Looking away can mean ignoring; it can also mean seeing and dismissing. It can mean deciding that even with a rose-colored filter, a photo of the shanties is still a document of suffering and not innocuous wall art. Let's look away, then, from the apparent victories sustained since I last wrote. The fact that the head of PEPFAR appointed under Obama is still running the program, the fact that the program is still running, that it hasn't lost its funding at all. Let's look away from that and past, through, toward, something else: the price of these "wins," which is not unlike the price-untallied, maybe even unnoticed-of working on an American-funded program that is more diligent and focused about saving foreign Black lives from AIDs deaths than any work happening on HIV within our borders. 
What I need you all to know is that to preserve the space that PEPFAR has carved out for working with and for adolescent girls and young women-beautifully and sometimes even close to revolutionarily-another language is underway. I wrote something similar last time concerning the Global Gag Rule, which eliminates all speech about abortion, but this is different. It is not a silence but a linguistic sliding that is happening.

The head of PEPFAR is one of the last Obama-era presidential appointeesif not the last such appointee — still at her post under the Trump administration. She is playing a high-stakes game to keep her job and keep the program running, and often she makes me want to stand and salute. But in these days, patriotism is shot through with desperation. The better route is looking away from the performance. So I must report on her diction shift, which has her now mentioning, in every single speech, the extreme prevalence of "first-sex-as-rape" among African girls. It is true and it is horrifying; it also forecloses a sex-positive conversation about girl's bodies and women's bodies that engages support by foregrounding pleasure. But pleasure has no place in the new talk that forefronts sex through depictions of an elevenyear-old girl who is raped by an older man. While there is abhorrent truth to this illustration, there is more owed to that girl as an adult or a teen: a place where she can reclaim her body, its strength and sensation, for herself after such abuse. The news from the COP review is that hers is not that world. Not right now.

AIDs funding will survive, I believe, by turning to old tropes of geographic instability and atrocities in countries far away-no more piles of bodies and coffin shops but now the violated girl child. What do we do when the language selected is true but insufficient? When the means to survival is to speak horror because it plays well with congressmen who consider themselves devout? Is this caring for that girl or is it adding, in some infinitesimal way, to her pain? Find your own version of this question. It is about capitulation, increments, and acceptable diction shifts. Ask it and then see what words your answer takes. How we speak will pave the road that lies ahead.

Whitbread: I won't lie; sex-positive approaches are kinda my thing. So, when I read Pato's statement, all I could think about was hanging out with my lovers at the bathhouse (why yes, they do have woman and trans bathhouse nights in Toronto) and inviting all the amazing activists I know for an extended period-a really extended period (COME!). Then, I thought that was selfish and gets into that whole queer island thing and 
that excludes many folks I care about, making me feel bad (or good, if for a day or two).

When we talk about wellness, where do self-care and self-preservation fit in? I have known way too many community activists that have left too soon because they were beaten down. About a year or so ago, I realized that everyone I knew who had died of AIDs had committed suicide. At that same time, I also thought, How come I haven't tried yet?

Mental health is underrepresented in our discussions. I don't think that people actually know how tough it is to keep on keeping on living and breathing this work. It is easy to get together with your pals, laugh it up and join a one-off protest, but then what? In some ways, I envy the people who can turn their social justice rah-rah on and then turn it off-Facebook repost and I've done my daily duty—ha! As if?!

How can movements better work together and understand the layers and layers of personal and societal hurt? There doesn't seem to be much space within our current activist culture for rest and healing. I don't know if it is because I just had twins, but I look at them and think, How can I focus in on you being as open and amazing and wonderful as possible? And how do I do this at the same time as all the other stuff on almost no sleep?

Rhee:

\section{AIDS Futures: A Poem in Response}

This blood, my veins, our AIDs Futures, I listen to you:

"I find myself walking into these basements hoping someone might show me how to pray." (Emily Bass)

Show us, as we hold our hands collectively because "None of this is impossible." (Quito Ziegler)

See the circular in the drawing, along with sun beams radiating out, outlines our eyes, and makes visions.

For a world of limitless care for Indigenous people, we fight for care, resist the cutbacks, and the incarceration.

(Elton Naswood)

"I believe acts of kindness are stronger than acts of fear." (Jessica Whitbread) 
Your words are kindness. So I release, fear. Fear runs as we organize, convene, disseminate, "... and follow the vision of new waves of leadership ..." (Pato Hebert)

Say, I am listening to you "Imagine Liberation."

It's a song I repeat.

After you, and over again.

Our chant

teaches us

how to pray.

\section{Notes}

1 "Elton Naswood."

2 Quito Ziegler, “If You Must,” accessed August 10, 2018, https://quitoziegler.com /bio/.

3 Juhasz, AIDS TV; Wald, Contagious.

4 These stories are available to the public at From the Center's Vimeo site, https://vimeo.com/user7696400. From the Center is a public humanities project, and the digital stories are screened in jails and prisons. For more about the project, see https://ourstorysf.wordpress.com/.

5 Sebelius, "National HIV/AIDs Strategy."

6 Ku et al., "Repealing Federal Health Reform."

\section{Bibliography}

Bass, Emily. "How to Survive a Footnote: AIDs Activism in the 'After' Years." In "As If," special issue, $n+123$ (Fall 2015). https://nplusonemag.com/issue-23/annals -of-activism/how-to-survive-a-footnote/.

Białoszewski, Miron. A Memoir of the Warsaw Uprising. Translated by Madeline G. Levine. New York: New York Review Books, 2015.

“Elton Naswood." Circle of Harmony. Accessed September 12, 2019. http:// www.aaihbcircleofharmony.org/index.php/planning-committee/planning -committee/elton-naswood/.

Juhasz, Alexandra. AIDS TV: Identity, Community, and Alternative Video. Durham, NC: Duke University Press, 1995.

$\mathrm{Ku}$, Leighton, Erika Steinmetz, Erin Brantley, and Brian Bruen. "Repealing Federal Health Reform: Economic and Employment Consequences for States.”

Commonwealth Fund, January 2017. 
Sebelius, Kathleen. “The National HIV/AIDs Strategy.” Presentation, Washington, DC, July 13, 2010. Excerpted in Frank James, "Obama Unveils First National HIV/AIDS Strategy." NPR: The Two Way, July 13, 2010. https://www.npr.org /sections/thetwo-way/2010/07/13/128494452/obama-unveils-first-national -hiv-aids-strategy.

Wald, Priscilla. Contagious: Cultures, Carriers, and the Outbreak Narrative. Durham, NC: Duke University Press, 2010. 